LA- $-9514-H S$

DE83 002921

\title{
Monitoring Tritium in Air Containing Other Radioactive Gases
}

\author{
Roland A. Jalbert
}

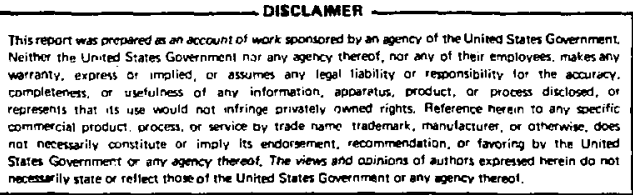

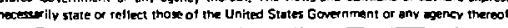

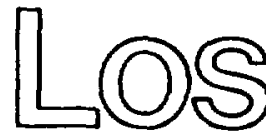


MONITORING TRITIUM IN AIR CONTAINING OTHER RADIOACTIVE GASES

by

Rol and A. Jalbert

ABSTRACT

A brief survey is presented of methods that have been developed for active tritium monitoring that may be applied $f$ mepsure trityium concentrations in air containing ${ }^{13} \mathrm{~N},{ }^{16} \mathrm{~N}$, and ${ }^{41} \mathrm{Ar}$ produced by $\mathrm{D}-\mathrm{T}$ neutrons. Included are instruments that empioy current subtraction to achieve discriminations and others that selectively remove atmospheric water vapor from the stream of activated air.

\section{INTRODUCTION}

Real-time monitoring of tritium in fission reactor environments is a longstanding problem because of the presence of ${ }^{41} \mathrm{Ar}$ and fission product gases. With few exceptions, the standard solutions have been to estimate the tritium concentration or to passively monitor for tritium using desiccants or bubblers.

However, passive monitoring is usually not an acceptable solution especially where tritium gas may be present in large quantities and releases to the room must be detected quickly. In the vicinity of high intensity $14-\mathrm{MeV}$ neutron sources or near fusion reactors using deuterium and tritium as the fuel gases, high concentrations of activated air (principally ${ }^{13} \mathrm{~N},{ }^{16} \mathrm{~N}$, and ${ }^{41} \mathrm{Ar}$ ) may be found at the same time and location where tritium may be released accidentally. Suitable instrumentation must be available that can discriminate in real time between tritium and the radioactive contaminants.

This report reviews some of the efforts that have been made to solve this instrumentation problem. The instruments used are examined and compared for their suitability for use at future fusion reactors. 


\section{TRITIUM REMUVAL FROM THE SAMPLED AIR}

Selective removal of tritium oxide from air being sampled is the principle behind bubblers (and desiccants) used in passive monitoring for tritium. In practice, the instrument becomes an active monitor if the bubbler is a continuous stream of water that is routed to a tritium counter. Such an instrument was developed and reported by Osborne in $1972^{1}$ and later refined. ${ }^{2}$

The air being sampled (for HTO) is bubbled through a continuously flowing stream of water that removes most (298\%) of the HTO but very little of the contaminant gases (i.e., noble gases; the instrument was developed for use at heavy water fission power reactors). Most of the radioactive gas picked up by the water is then removed by bubbling clean purging air or nitrogen through the stream before it is routed to a plastic scintillation counter.

As reported, background is $0.2 \mathrm{cps}$ and the overall sensitivity to tritium is $0.1 \mathrm{cps}$ per $\mu \mathrm{Ci} / \mathrm{m}^{3}$ (air). Thus, $1 \mu \mathrm{Ci} / \mathrm{m}^{3}$ is detectable in about $180 \mathrm{sec}$ onds.* A given concentration in air of noble gas results in a signal that is less than $7 \times 10^{-3}$ of that from the same concentration of tritium (i.e., the "discrimination factor" is $>140$ ). Both the sensitivity and the discrimination ability of the instrument can be improved by the use of a liquid scintillation counter but at added initial and operational cost and compiexity.

Discrimination against activated air may be worse than against noble gases since the solubility of ${ }^{13^{N 0}} \mathrm{x}$ (believed to be the chemical form of ${ }^{13_{N}}$ ) in water is higher than that of krypton and xenon. However, if used with fusion devices, the sampled air stream would have to be routed first through a catalyst to oxidize any elemental tritium to the oxide form.

Although the sensitivity of Osborne's instrument has been increased by mixing the sampled air directly with liquid scintillation cocktail flowing to a counting cell, ${ }^{3}$ the potential of this improvement for discrimination against contaminant gases has yet to be tested or, at least, reported.

*The minimum detectable concentration of tritium is defined as that concentration that results in a count equal to three times the standard deviation of the background count during the same time interval (99.7\% confidence). 
III. OTHER SCINTILLATION METHODS

Instead of removing the tritiated moisture from the sampled air by mixing it with scintillation cocktail or with water that flows to a counting cell, the moisture may be condensed and the condensate routed to a scintillation flow cell. Gibson and Burt ${ }^{4}$ cooled the sampled air to $1^{\circ} \mathrm{C}$ and the condensate, flowing at $38 \mathrm{l} / \mathrm{h}$, was subsequently counted in a flow cell filled with anthracene crystals. Sensitivity, dependent on the relative humidity, is 250 cps per $\mu \mathrm{Ci} / \mathrm{m}^{3}$ (air) at $58 \%$ humidity. With a background of $8 \mathrm{cps}$, a chronic level of $0.4 \mu \mathrm{Ci} / \mathrm{m}^{3}$ may be continuously measured. According to the authors, the instrument "does not detect radioactive gases such as ${ }^{41}$ Ar." Unfortunately no other information is given.

The above system is fairly complex, as is the case of a more recent version designed by Singh and Kariwani. ${ }^{5}$ In their instrument, the counting cell, which is made of Perspex, is packed with "plastic scintillation powder." At 50\% humidity, the sensitivity is $500 \mathrm{cps}$ per ${ }_{\mu} \mathrm{Ci} / \mathrm{m}^{3}$. With a background of $50 \mathrm{cps}$ the minimum tritium detectibility is about $0.01 \mu \mathrm{Ci} / \mathrm{m}^{3}$ in $18 \mathrm{~s}$. The humidity dependency problem was solved by providing the capability of humidifying the incoming air, if desired, but at a sacrifice of sensitivity. Although the system was designed for use in the working areas of heavy-water-moderated reactors, its performance in the presence of noble gases or ${ }^{41}$ Ar was not reported. Both systems would be expected to have a rather long response time (many minutes), respond slowly to changes in concentration, and would need a catalyst if used to monitor tritium gas.

\section{DUAL-CHAMBER SUBTRACTIVE METHOD}

One of the simplest methods for monitoring for tritiated water vapor in the presence of contaminant gases is to use two flow-through ion chambers, one of which measures the concentration of the radioactive gases in the air from which tritium, as the oxide, has first been removed by a drier. The second chamber measures the total current including that from tritium. The chamber currents are then subtracted leaving only that from the tritiun. The chambers may be placed in series with the drier placed between the chambers or preferably, if the concentrations may change rapidly with time, in parallel. 
One such system has been developed by Osborne and Coveart ${ }^{6}$ for use at CANDU heavy water power reactors in Canada. The system uses four 1.3- $\ell$ chambers: two assemblies of two concentric chambers each, the outer chambers being the flow-through gas-measuring chambers, and the inner, closed chambers for gamma compensation. These assemblies are arranged in a parallel configuration. The sampled air is split into two streams, one of which is routed directly to one of the flow chambers. The other stream passes through one of two desiccant cartridge driers on its way to the other flow chamber. The driers are alternately used and regenerated automatically every $30 \mathrm{~s}$. The system, which is 1 arge, complex, and heavy $(150 \mathrm{~kg})$, is mounted on a carriage for transportability.

Sensitivity of the instrument to tritium is of the order of a few $\mu \mathrm{Ci} / \mathrm{m}^{3}$, whereas its rasponse to noble gas is $4-20 \%$ of that of an equivalent concentration of tritiur:, the percentage depending on the particuiar gas. The discriminating factor is thus only 5-25, somewhat less than that of 0sborne's "water pick-up" system described earlier. The discrimination could be improved by matching chambers more carefully, or al ternative?y, by adjusting the volumes with a compensating electrode in the larger chamber or by the use of separate electrometers for the two chambers.

v. PROPORTIONAL COUNTING

Another method that has the similar advantage of high sensitivity but with the disadvantage of requiring a counting medium is proportional counting. Such instruments can be designed with inherent ability to discriminate against contaminant gases by using guard chambers and coincidence and anticoincidence circuitry. One advantage of such instruments is that they have been in use in Europe for several years and are now commercially available. One such instrument is the model SMHK made by Munchener Apparatebau.* In this instrument the background is $0.08 \mathrm{cps}$ and the tritium sensitivity is $8.3 \mathrm{cps} \mathrm{per} \mu \mathrm{Ci} / \mathrm{m}^{3}$. For ${ }^{133} \mathrm{Xe}$, the coincidence and anticoincidence counting rates are reported to be 8.3 and $0.55 \mathrm{cps}$ per $\mu \mathrm{Ci} / \mathrm{m}^{3}$, respectively.

The coincidence circuit permits a measure of the concentration of the contaminant gas, whereas the anticoincidence circuit gives the concentration of

\#Munchener Apparatebau, Postfach 144, 8012 Ottobrunn, Federal Republic of Germany. 
tritium gas plus some remaining counts from the contaminant. Subtraction of the latter counts is done automatically based on the concentration of the gas determined by the coincidence rate and an experimentaliy determined "compensation factor." Thus, using the same detectability criterion, iche $M D C_{T}\left(\mu C i / m^{3}\right)$ is

$$
0.07 \sqrt{\frac{C_{C}}{t}},
$$

where $C_{c}\left(\mu \mathrm{Ci} / \mathrm{m}^{3}\right)$ is the concentration of the contaminant and $t(s)$ is the counting time. Background was neglected.

Although the instrument is fairly sensitive, being able to measure about $0.01 \mu \mathrm{Ci} / \mathrm{m}^{3}$ in $2100 \mathrm{~s}$ under ideal conditions, it is limited at high concentrations. Saturation becomes apparent at $2200 \mu \mathrm{Ci} / \mathrm{m}^{3}$ (tritium) and the instrument reads $235 \%$ low at $10^{3} \mu \mathrm{Ci} / \mathrm{m}^{3}$.

Another disadvantage of this instrument is the need for, and cost of, a counting gas--either methane or very pure natural gas--which flows at approximately $30 \mathrm{l} / \mathrm{h}$, twice the rate of the sampled air. Moreover, the instrument's behavior in the presence of a mixture of ${ }^{13} \mathrm{~N}, 16_{\mathrm{N}}$, and ${ }^{41} \mathrm{Ar}$, the ratio of whose concentrations may change due to mixing and radioactive decay, is unknown. The compensation factor* for ${ }^{14} \mathrm{C}$ is about $18 \%, 27 \%$ for ${ }^{133} \mathrm{Xe}$, and $25 \%$ for a mixture of noble gases.

VI. DUAL SIGNAL SUBTRACTIVE METHODS WITHOUT TRITIUM REMOVAL

The weak beta energy of tritium suggests another subtractive technique based on the gamma rays and much higher beta energies of contaminant gases. Soudain $^{7}$ in 1966 reported on a flow-through ion chamber in the wall of wich was placed an end-window G-M tube that responded only to the contaminant gases. The tritium betas could not penetrate the $2-\mathrm{mg} / \mathrm{cm}^{2}-$ thick window of the G-M tube. If it were desired to balance the outputs of the two detectors electronically, such an instrument would be expected (1) to have a large transient response due to the geometry differences of the G-M tube and chamber if the concentration of the contaminant gas were to change suddenly, (2) to be very sensitive to changes in the relative concentrations or multiple contaminants due to the energy sensitivity of the G-M counter, and (3) to produce a net current upon subtraction of

\#The compensation factor is the percentage of coincidence counts showing up in the anticoincidence channel for a particular gas. 
the G-M and chamber currents that is very noisy due to the 10 number of statistical events in the G-M tube (compared with those in the chamber). The system as reported actually did not attempt to match the output currents of the chamber and counter for a given contaminant gas. Rather, the two outputs were transmitted to a two-channel recorder and the concentration of tritium was subsequent$1 y$ determined by calculation using the measured calibration factors of the two detectors.

More recently, a prototype instrument similar in principle to Soudain's was developed and described originally in Ref. 8 and finally in Ref. 9. Instead of using a G-M tube for subtraction, the instrument employs a separate outer chamber concentric with the inner flow-through chamber. A thin wall common to both chambers is opaque only to the tritium betas and the weaker betas of the contaminant gas. Currents produced in the two chambers are automatically subtracted, leaving only the current due to tritium. The instrument has irherently better statistical properties, better geometry, and iess energy dependence than the instrument developed by Soudain. The minimum detectable concentration of tritium using a long 1- 2 sampling chamber in a background concentration of ${ }^{85} \mathrm{Kr}$ is

$$
1.4 \sqrt{\frac{C_{K}}{t_{C}} \mu \mathrm{Ci} / \mathrm{m}^{3}},
$$

where $C_{K}\left(\mu \mathrm{Ci} / \mathrm{m}^{3}\right)$ is the concentration of krypton gas and $t_{C}(s)$ is the electronic time constant. For example, with a 60-s time constant, tritium concentrations of about $1 \mu \mathrm{Ci} / \mathrm{m}^{3}$ to $100 \mu \mathrm{Ci} / \mathrm{m}^{3}$ can, in principle, be measured in background krypton concentrations of $10 \mu \mathrm{Ci} / \mathrm{m}^{3}$ to $10^{5} \mu \mathrm{Ci} / \mathrm{m}^{3}$, respectively. In practice, these ideal detectable limits can be approached to within a factor of 2 or 3.

\section{USE OF SEMIPERMEABLE MEMBRANES}

Separation of tritiated water vapor from other gases may be accomplished by the use of semipermeable membranes, wich have a much higher permeability for HTO than for the contaminant gases. Howel1, Cate, and Wong ${ }^{10}$ have made measurements of gas permeation using HTO, HT, and $\mathrm{Kr}$, and a number of membrane materials. For instance, for dimethyl silicone, the ratio of gas permeabilities of HTO to HT is 55 ; of HTO to $N_{2}, 120$; and of HTO to Ar, 60 . The concen- 
tration ratio enhancement should be approximately equal to these values. The final concentrations of course depend on the choice of membrane, its thickness and area, and on the flow rates on both sides of the membrane, particularly on the detector side. One disadvantage is the slow response time, measured to be il min with the final concentration reading equilibrium in about 5 minutes.

Another material with extremely high permeability for water vapor is a Dupont product called Nafion. It is commercially available in tubing form from Dupont or from Perma-Pure Dryer, ${ }^{*}$ which arranges bundles of Nafion tubing in a steel drying tube for commercial applications. Its permeability to HT is about $10^{4}$ times lower than for water vapor although in practice the separation that can be achieved is closer to $10^{3} .11$ Preliminary measurements of the permeabilities of $\mathrm{Ar}$ and $\mathrm{NO}_{\mathrm{x}}$ (believed to be the chemical form of the $13_{\mathrm{N}}$ produced by $D-T$ neutrons) indicate that they are probably about $10^{3}$ to $10^{4}$ lower than that of HTO. As in the case of the dimethyl silicone, the breakthrough and memory times are fairly long, making its use impractical for monitoring rapidly changing concentrations. Two instruments under current development use Nafion tubes for discriminating between HT and HTO. One approach uses ion-chamber detectors whereas the second uses proportional counting for better sensitivity and better discriminating ability against background radiation.

Where enhancement of the concentration of HTO over those of other radioactive gases is important, membranes may be used to advantage provided the memory effect is not a problem. However, for monitoring tritium gas in the presence of other contaminants, the gas would first have to be oxidized. Differentiating between HTO and HT with or without other radioactive gases present is certainly one of its more promising applications, which could well compete with subtractive methods that depend on the complications of multiple chambers and desiccants.

\section{DISCUSSION}

For active monitoring of (the total) tritium in the presence of radioactive gases, there are a number of possible techniques or systems that may be used depending on the concentration of background gases expected, the sensi-

\#Perma-Pure Dryer, Box 70, Oceanport, NJ 07757. 
tivity, response time, and cost. Properties of some systems that have been reported and briefly described here are summarized in Table I.

For monitoring tritium gas, the methods that require that tritium be in the form of water vapor necessitate, of course, the addition of a catalyst to the system. The first problem that this presents is that high concentrations of hydrogen gases that may be present may cause problems of condensation in the instrument lines and measuring chamber beyond the point of oxidation. In instruments that effectively measure the tritium concentration of the moisture in the air, to convert the result to air concentration would te difficult if not impossible if there are unknown quantities of hydrogen, deuterium, and inactive water vapor accompanying the tritium in the sampled air.

For monitoring air for tritium that may be found in either the elemental or water vapor form, instruments that do not convert the elemental tritium to the oxide are to be preferred. Of these, the one with the highest sensitivity is the proportional counter, which can be designed for good cancelling ability,

TABLE I

\section{PERFORMANCE COMPARISON}

\begin{tabular}{|c|c|c|c|c|c|c|}
\hline & $\begin{array}{l}\text { Water Pick-Up/ } \\
\text { Plastic Scint }\end{array}$ & $\begin{array}{l}\text { Cont inuous Hater } \\
\text { Condensation/Scint }\end{array}$ & $\begin{array}{l}\text { Dual Separate } \\
\text { Chamber and } \\
\text { Desiccant }\end{array}$ & $\begin{array}{l}\text { Ion chamber and } \\
G-M \text { Counter }\end{array}$ & $\begin{array}{l}\text { Dual Concentric } \\
\text { Ion Chamber }\end{array}$ & $\begin{array}{l}\text { Proportional } \\
\text { Counter }\end{array}$ \\
\hline $\begin{array}{l}\text { Tritium } \\
\text { sensitivity } \\
\text { (with no } \\
\text { contaminant gas) } \\
(\mathrm{uCi} / \mathrm{m} \text { ) }\end{array}$ & $(\ln 200 \mathrm{~s})$ & $\leq 0.1$ & I & $5^{d}$ & 2)-5 & $\left(\begin{array}{c}0.01 \\
(1 \mathrm{n} 21 \text { min })\end{array}\right.$ \\
\hline $\begin{array}{l}\text { Discrimination } \\
\text { Factor for a } \\
\text { contzaminant } \\
\text { gas }\end{array}$ & $\begin{array}{c}140 \\
\text { (depends on } \\
\text { gas) }\end{array}$ & $?^{c}$ & $\begin{array}{c}5-25 \\
\text { (depending } \\
\text { on gas) }\end{array}$ & -- & $-\cdot$ & -- \\
\hline $\begin{array}{l}\mathrm{MDC}_{\mathrm{T}} \text { in presence } \\
\text { of } \mathrm{C}_{\mathrm{HE}} \text { in } t(\mathrm{~s})^{\mathrm{b}} \\
\left(\mu \mathrm{C}\left(1 / \mathrm{m}^{3}\right)\right.\end{array}$ & -- & $-\cdots$ & -- & $?$ & & 0.07 \\
\hline $\begin{array}{l}\text { Suitability for } \\
\text { HTO or HT }\end{array}$ & Кто & HTO & HTO & HTO/HT & HTO/HT & HTO/HT \\
\hline
\end{tabular}

"The Discrimination Factior is defined as the concentration of the contmination gas that results in a signal equal to that of a unit concentration of tritiun.

$b_{M D C}=$ Minimum detectable concentration of tritium. $C_{H E}=$ concentration of contaminant gas in $\mathrm{MCH}_{\mathrm{H}} \mathrm{m}^{3}$.

${ }^{c}$ Should be fair (one author clains ${ }^{41}$ Ar was not seen but no data were given).

Estimated.

'Should be higher than that of dual coscentric chamber system. 
at least for a single accompanying contaminant gas. Its disadvantages include the need for a counting gas, its operating range 1 imited to a maximum of $210^{2}-10^{3}{ }_{\mu \mathrm{Ci}} / \mathrm{m}^{3}$, its complexity and cost, and its presently unknown and questionable ability for handling multiple contaminants. The second possibility, with less sensitivity (by about two orders of magnitude) and less cancelling ability (by 21 order of magnitude), is the concentric ion-chamber system, whose obvious advantages are simplicity and corresponding lower cost. These two instruments, then, are ones that may be considered for monitoring fusion reactor halls or other similar (neutron) environments where tritium gas in large quantities is handled.

The use of drying tubes to separate HTO from background gases is a promising approach. It offers in one instrument the ability to measure separately the concentrations of HTO and HT in a background of activated air. A catalyst would be needed to oxidize the HT to HTO and at least three drying tubes would be required to obtain adequate separations of the HTO from HT. More work is needed, however, to verify the permeation rates of the $\mathrm{NO}_{\mathrm{x}}$ and $\mathrm{Ar}$ under realistic conditions and to improve the poor response times.

\section{REFERENCES}

1. R. V. Osborne, "Development of a Monitor for Tritiated Water Vapcur in the Presence of Noble Gases," Atomic Energy of Canada Limited report AECL 4303 (September 1972).

2. R. V. Osborne, "Central Tritium Monitor for CANDU Nuclear Power Stations," IEEE Trans. on Nucl. Sci., NS-22, 676-680 (1975).

3. R. V. Osborne and N. W. Tepley, "Monitoring Tritiated Water in Air and Water Effluents," presented at the Health Physics Society Eleventh Midyear Topical Symposium on Radiation Instrumentation, San Diego, January 17-19, 1978.

4. J. A. B. Gibson and A. K. Burt, "A Method for Continuous Measurement of Tritiated Water in Air," J. Nucl. Energy, Parts A/B 20, 185-190 (1966).

5. A. N. Singh and M. G. Kadwani, "A Sensitive Detector System for the Continuous Monitoring of Tritium in the Air," IEEE Trans. Nucl. Sci. NS-21, 188-193 (1974).

6. R. V. Osbarne and A. S. Coveart, "A Transportable Monitor for Tritiated Water Vapour," Atomic Energy of Canada Limited report AECL 6097 (1977).

7. G. Soudain, "Contribution a la dosimetrie du tritium en presence de gas inactifs ou actifs," Commissariat a l'Energie Atomique report CEA-R 2841 (1966). 
8. R. A. Jalbert, "A Monitor for Tritium ir. Air Containing Other Beta Emitters," Trans. of the Am. Nuclear Soc. 22, 739-740 (1975).

9. R. A. Jalbert, "A Tritium Monitor for Fusion Reactors," Los Alamos National Laboratory report LA-9382-MS (1982).

10. R. H. Howell, J. C. Cate, and C. Wong, "Separation of HT, Noble Gases and HTO Vapor with Semipermeable Membranes," Nucl. Inst. and Methods 127, 579-583 (1975).

11. R. V. Osborne and R. G. C. McElroy, "Applications of Membranes to Monitoring for Tritiated Water Vapour," presented at the International Symposium on Management of Gaseous Wastes from Nuclear Facilities, Vienna, February 18-22, 1980. 